\title{
Utilização dos resíduos da extração do óleo bruto do café na produção de material adsorvente
}

\author{
Luciano Luiz Silva*, Ana Paula Capelezzo, Stefane Vieira Besegatto* \\ Flavia Conto, Suellen Cadorin Fernandes, Murilo Cesar Costelli* \\ Juliana Savio, Gustavo Lopes Colpani, \\ lucianols@unochapeco.edu.br
}

\begin{abstract}
Resumo
Uma alternativa viável e eficaz no tratamento de efluentes é o uso de carvão ativado. Este trabalho possui por objetivo a obtenção de um carvão ativado utilizando como material percursor café torrado que passou por um processo prévio de extração, para retirada do óleo bruto, que atue no tratamento do corante azul de metileno. Os materiais foram caracterizados através da determinação da área superficial BET. A cinética de adsorção foi determinada experimentalmente e os modelos comparados aos modelos matemáticos de pseudoprimeira e pseudossegunda ordem, sendo que o modelo de pseudossegunda ordem descreveu mais adequadamente a cinética de adsorção com qe $=103,09 \mathrm{mg} \cdot \mathrm{g}^{-1}$ para C1 e $62,89 \mathrm{mg} \cdot \mathrm{g}^{-1}$ para C2. A capacidade de adsorção de surfactantes aniônicos no equilíbrio obedeceu ao modelo de Langmuir para C1, apresentando $\mathrm{K}$ de 2,125 L.mg ${ }^{-1}$ e qmax de 588,235 mg.g ${ }^{-1}$ e a isoterma de Freundlich apresentou o melhor ajuste aos dados de equilíbrio para $\mathrm{C} 2$, sendo os resultados obtidos para KF e $\mathrm{n}$ iguais a 51,019 $\left(\left(\mathrm{mg} . \mathrm{g}^{-1}\right) .\left(\mathrm{L} \cdot \mathrm{mg}^{-1}\right) 1 / \mathrm{n}\right)$ e 3,104, respectivamente. O ponto de carga zero para C1 está na faixa de 2,001 - 2,009 e C2 de 2,0013. Os resultados demonstraram ambos os carvões ativados são eficientes na remoção de corantes catiônicos.

Palavras Chave: adsorção; carvão ativado; café torrado; isotermas; cinéticas de adsorção.
\end{abstract}

\begin{abstract}
A viable and effective alternative in the wastewater treatment is the use of activated carbon. This study has the objective to obtain an activated carbon produced from roasted coffee which had its gross oil extracted previously. This activated carbon will act in the treatment of methylene blue dye. The materials were characterized by determination of the BET surface area. The adsorption kinetics was determined experimentally and the models were compared to mathematical models of pseudo first order and pseudo second order. The pseudo second order model described better the adsorption kinetics with qe $=103.09 \mathrm{mg} \cdot \mathrm{g}^{-1}$ for $\mathrm{C} 1$ and $62.89 \mathrm{mg} \cdot \mathrm{g}^{-1}$ for $\mathrm{C} 2$. The adsorption capacity of anionic surfactants in equilibrium followed the Langmuir model for $\mathrm{C} 1$, with $\mathrm{K}=$ 2.125 L.mg-1 and e qmax de 588.235 mg.g ${ }^{-1}$ and the Freundlich isotherm showed the better fit to the equilibrium datas for C2. The results obtained for KF and $\mathrm{n}$ were equal to $51.019\left(\left(\mathrm{mg} \cdot \mathrm{g}^{-1}\right)\right.$. $\left(\mathrm{L} . \mathrm{mg}^{-1}\right)^{1 / n}$ ) and 3.104, respectively. The point zero charge for C1 is in the range of $2.001-2.009$ and $\mathrm{C} 2$ of 2.0013. The results showed that both activated carbons are effective to remove cationic dyes.
\end{abstract}

key words: adsorption; activated carbon; toasted coffee; isotherms; adsorption kinetics.

*Universidade Comunitária da Região de Chapecó - Unochapecó 


\section{INTRODUÇÃO}

$\mathrm{O}$ $s$ problemas ambientais têm se tornado cada vez mais críticos e frequentes, desta forma a preocupação com a preservação do meio ambiente enfatiza o interesse pela busca de materiais de baixo custo que possam ser utilizados como adsorventes para eliminação de contaminantes em efluêntes. Dentre os materiais mais empregados, destaca-se o carvão ativado que apresenta excelentes características adsorventes (PEREIRA et al., 2008).

O carvão ativado é um material carbonáceo e poroso preparado pela ativação e carbonização de substâncias orgânicas, principalmente de origem vegetal (BRUM et al., 2007). Apresenta uma forma microcristalina, não grafítica e sofre um processamento para aumentar a porosidade interna (CLAUDINO, 2003). Seu poder adsorvente é proveniente da alta área superficial e da presença de uma variedade de grupos funcionais em sua superfície (GUILARDUCI et al., 2006).

Mais de 10 mil tipos de corantes são empregados anualmente pelas indústrias, o equivalente a cerca de 700.000 ton/ano. No Brasil, utiliza-se cerca de 26.500 ton/ano, correspondendo a um percentual de aproximadamente $4 \%$ do total de corantes usados nas indústrias em todo o mundo. Boa parte deste material é descartada nos corpos hídricos, representando um problema ambiental e perda na rentabilidade da indústria, acarretando em desperdício de matéria-prima (MONTEIRO, 2010).

Os corantes são visualmente detectáveis e causam sérios problemas de natureza estética nos corpos d'água receptores, mesmo quando presentes em pequenas quantidades. Além disso, a maioria dos corantes é resistente à biodegradação, à fotodegradação e à ação de agentes oxidantes e alguns são suspeitos de induzirem efeitos carcinogênicos e/ou mutagênicos (NEUMANN et al., 2000).

O azul de metileno é um corante catiônico bastante empregado na indústria, sendo utilizado no tingimento de algodão, lã, papel, tinturas temporárias para cabelos, entre outros (WU et al., 2009). Este corante é muitas vezes empre- gado como composto modelo na remoção de corantes e contaminantes orgânicos presentes em soluções aquosas, em consequência à sua forte adsorção em suportes sólidos (HAMEED et al., 2007). Ainda, apresenta-se como um composto pouco tóxico quando comparado aos metais pesados, porém, a exposição aguda pode causar efeitos prejudiciais à saúde como aumento dos batimentos cardíacos, dor de cabeça intensa, náuseas, vômitos, diarreia e necrose do tecido humano e, ainda, alterar a estabilidade biológica dos ecossistemas circundantes, retardando a atividade fotossintética, inibindo o crescimento da biota, podendo quelar íons metálicos que produzem microtoxicidade para os peixes e outros organismos (SENTHILKUMAAR, et al., 2005; SHENG et al., 2009).

Muitos métodos físicos e químicos são empregados para o tratamento de efluentes contendo corantes, tais como, adsorção, eletroquímica, precipitação, filtração, ozonização entre outros. Técnicas de tratamento fundamentadas em processos de coagulação, seguidos de separação por flotação ou sedimentação, apresentam elevada eficiência na remoção de material particulado. No entanto, a remoção de cor e de compostos orgânicos dissolvidos é ineficiente empregando tais técnicas, sendo os processos de adsorção por carvão ativado mais eficientes (KUNZ et al., 2002).

$\mathrm{Na}$ adsorção ocorrem interações físicas e/ou químicas entre as moléculas de um fluido e a superfície de um sólido (GOMIDE, 1980). Essa operação depende da área superficial e do volume dos poros. De acordo com Oliveira (2010) o primeiro passo para um processo de adsorção eficiente é a escolha de um adsorvente com alta seletividade, capacidade e longa vida. Este deve também estar disponível em grandes quantidades a um baixo custo.

$\mathrm{Na}$ busca por materiais alternativos para a produção de adsorvente, o estudo realizado por Lopes et al. (2013), propõe a obtenção de um carvão ativado a partir do pseudofruto da Hovenia dulcis Thunberg (uva-Japão), avaliando a influência de diferentes parâmetros de processo como massa, tempo e temperatura e a viabilidade de seu uso como adsorvente de 
baixo custo para a remoção do corante azul de metileno. De forma análoga, o estudo realizado por Bugiereck et al. (2013), apresenta a produção de carvão ativado a partir de casca de banana.

Segundo a Companhia Nacional de Abastecimento - CONAB o Brasil é um dos maiores produtores mundiais de café, com uma estimativa para a produção da safra cafeeira 2016 que pode variar entre 49,13 e 51,94 milhões de sacas de 60 quilos de café beneficiado (CONAB, 2016). Com a crescente produção do grão, cresce também a aplicabilidade do mesmo, nos mais diversos segmentos da indústria como alimentícia, cosméticos e perfumaria.

Em consequência da elevada produção, há também uma elevada geração de resíduos do café, originados desde seu beneficiamento até o consumo na forma de bebida. Estes são destinados na sua maioria para a indústria de ração animal, adubos e na queima como combustíveis (EMBRAPA, 2012). Uma alternativa para aumentar o valor agregado aos resíduos do café é a produção de carvão ativado, na qual estudos têm sido realizados obtendo-se resultados satisfatórios para uso desses carvões como adsorventes de substâncias tóxicas e poluentes ambientais (FONSECA, 2013).

Giraldo \& Pirajan (2012) utilizaram resíduos de café como precursores na obtenção de carvão ativado visando aplicação na adsorção dos íons de mercúrio II (Hg II) e zinco II (Zn II). Khenniche \& Aissani (2010) preparam um carvão ativado a partir de restos de café usando a ativação química com cloreto de zinco $\left(\mathrm{ZnCl}_{2}\right)$. Cinco carvões foram preparados variando a proporção do agente ativante (massa de $\mathrm{ZnCl}_{2} /$ massa de resíduo de café) de $0 \%$ a $100 \%$, sendo que a ativação com uma proporção igual a $25 \%$ foi a mais eficaz na adsorção do fenol, removendo cerca de $68 \%$ do poluente. Phatai et al. (2014) estudaram a eficiência de adsorção do corante violeta de metilo fazendo o uso de carvão ativado oriundo de resíduos de café. Os resultados mostraram que a adsorção máxima de corante ocorreu com um tempo de contato de $60 \mathrm{~min}$, o pH da solução de 9,0 e 0,3 g de adsorvente.
Diante do exposto, o presente trabalho visa testar a capacidade de adsorção do corante azul de metileno a partir do emprego de um carvão ativado quimicamente com ácido fosfórico utilizando como precursor café torrado que passou por um processo prévio de extração do seu óleo bruto.

\section{Metodologia}

\section{Materiais}

O material precursor utilizado para a obtenção do carvão ativado foi o café torrado adquirido no Clube do Café de São Paulo, sendo que o mesmo passou por um processo prévio de extração de seu óleo bruto, utilizando-se para tal a técnica de extração supercrítica, sendo o solvente utilizado o dióxido de carbono $\left(\mathrm{CO}_{2}\right)$, o qual é considerado um solvente ambientalmente correto em virtude de apresentar características como atoxicidade, não inflamável e de custo relativamente baixo.

\section{Obtenção do carvão ativado}

Para a obtenção do carvão ativado, bem como as cinéticas e isotermas de adsorção utilizou-se a metodologia proposta por Colpani (2012) com algumas adaptações. Inicialmente preparou-se uma solução (1:1) de ácido fosfórico 85\% (marca Vetec) e água destilada, contemplando um volume total de $150 \mathrm{~mL}$. Pesou-se $30 \mathrm{~g}$ de amostra seca e adicionouse a solução ácida. A solução foi encaminhada a um shaker (marca Dist modelo DST 01) em uma temperatura de $85^{\circ} \mathrm{C}$ onde a solução foi mantida em agitação moderada de aproximadamente $60 \mathrm{rpm}$ durante $1 \mathrm{~h}$. Decorrido este período as amostras foram postas em cadinhos de porcelana e encaminhados à estufa (marca Quimis modelo Q $317 \mathrm{M}$ ) por $24 \mathrm{~h}$ a $85^{\circ} \mathrm{C}$.

Os cadinhos foram transferidos para a mufla (marca Quimis), sendo as temperaturas de carbonização de $500^{\circ} \mathrm{C}$ (amostra C1) e $600^{\circ} \mathrm{C}$ (amostra C2) por um tempo de $2 \mathrm{~h}$, com taxa de aquecimento de $10^{\circ} \mathrm{C} \cdot \mathrm{min}^{-1}$, sendo posteriormente armazenados em dessecador. O carvão 
foi então lavado com água destilada a aproximadamente $90^{\circ} \mathrm{C}$ e filtrado. Nesta etapa ainda estabilizou-se o pH entre 6 a 7 utilizando bicarbonato de sódio sendo lido em pHmetro (Quimis modelo Q $400 \mathrm{M}$ ).

As amostras foram secas em estufa à $110^{\circ} \mathrm{C}$ por $24 \mathrm{~h}$ para a remoção de quaisquer traços de umidade. O carvão seco foi macerado até apresentar-se como um pó fino e, então armazenado em frascos de âmbar para posterior utilização nos demais ensaios.

\section{Análise morfológica}

A morfologia dos materiais obtidos foi caracterizada através do método de Brunauer, Emmett e Teller (BET) utilizando o equipamento JEOL JSM-6390LV, obtendo-se desta forma dados de área superficial, volume do poro e tamanho do poro.

\section{Cinética de adsorção}

Os experimentos para avaliar as cinéticas de adsorção foram realizados empregando-se $1 \mathrm{~g}$ de carvão para cada $500 \mathrm{~mL}$ de solução de azul de metileno com concentração de 100 mg. $\mathrm{L}^{-1}$.

O sistema foi mantido sob agitação constante a uma temperatura de $20^{\circ} \mathrm{C}$ através de banho termostático no intuito de manter as propriedades do efluente quando em processo industrial de tratamento.

Uma amostra da solução de azul de metileno foi resguardada para posterior análise de absorbância no tempo zero, antes que o carvão ativado fosse adicionado ao mesmo. Em seguida, alíquotas de $1 \mathrm{~mL}$ eram retiradas em diferentes tempos de processo a fim de medir a absorbância da solução de azul de metileno. As amostras foram retiradas em 5, 10, 20, 30, 40, $50,60,90,120,150$ e $180 \mathrm{~min}$, posteriormente as mesmas foram diluídas e centrifugadas (marca Excelsa II modelo 206 BL) a 3300 rpm e 7 min por amostra, para garantir a deposição de qualquer material particulado tornando possível a leitura em espectrofotômetro (Bioespectro modelo SP 220), utilizando-se um comprimento de onda de $625 \mathrm{~nm}$. Os ensaios de cinética de adsorção foram conduzidos em triplicata, bem como os resultados foram expressos em mg. $1^{-1}$ através da curva de calibração, a qual foi definida a partir dos resultados de absorbância indicados para as concentrações de azul de metileno iguais a 0,$10 ; 0,50 ; 1,00 ; 2,00 ; 4,00$; 5,$00 ; 7,00 ; 10,00$ e 15,00 mg. $1^{-1}$.

\section{Cinética de pseudoprimeira ordem}

A cinética de pseudoprimeira ordem foi proposta por Lagergren em 1898, sendo descrita na Equação 1 e linearizada na Equação 2.

$$
\begin{aligned}
& \frac{D_{q}}{D_{t}}=\mathrm{k}_{1}\left(\mathrm{q}_{e}-\mathrm{q}\right) \\
& \mathrm{L}_{n}\left(\mathrm{q}_{e}-\mathrm{q}\right)=\mathrm{L}_{n} \mathrm{q}_{e}-\mathrm{K}_{1} * \mathrm{t}
\end{aligned}
$$

Onde:

$\mathrm{k}_{1}=$ constante da velocidade de adsorção pseudoprimeira ordem $\left(\mathrm{min}^{-1}\right)$. $\mathrm{t}=$ tempo de adsorção ( $\mathrm{min}$ ).

$\mathrm{q}_{e}=$ quantidade adsorvida no equilíbrio (mg.g $\left.{ }^{-1}\right)$.

Os valores obtidos para $\mathrm{K}_{1}$ representam a constante da taxa de adsorção de pseudoprimeira ordem $\left(\mathrm{s}^{-1}\right)$, e $\mathrm{q}_{e}$ e q são as quantidades adsorvidas por grama de adsorvente no equilíbrio e no tempo $\mathrm{t}$, respectivamente $\left(\mathrm{mg}^{\mathrm{g}} \mathrm{g}^{-1}\right)$.

\section{Cinética de pseudossegunda ordem}

A cinética de pseudossegunda ordem, fundamentada na adsorção de equilíbrio é expressa na Equação 3 e sua linearização na Equação 4 .

$$
\begin{aligned}
& \frac{D_{q}}{D_{t}}=\mathrm{k}_{2}\left(\mathrm{q}_{e}-\mathrm{q}\right)^{2} \\
& \frac{1}{q_{t}}=\frac{1}{k_{2} q_{e^{2}}}+\frac{t}{q_{e}}
\end{aligned}
$$

Onde:

Onde $\mathrm{k}_{2}$ é a constante da taxa de adsorção da pseudossegunda ordem expressa em g.mg ${ }^{-1} \cdot \min ^{-1}$. 


\section{Isoterma de adsorção}

Fez-se o uso de 9 erlenmeyers cada qual contendo 0,$1 ; 0,2 ; 0,3 ; 0,4 ; 0,5 ; 0,6 ; 0,7 ; 0,8$ e $0,9 \mathrm{~g}$ de carvão devidamente identificados e pesados. Adicionou-se a cada um destes erlenmeyers $100 \mathrm{~mL}$ de uma solução de 400 mg. $\mathrm{L}^{-1}$ de azul de metileno. É necessário que o pH da solução esteja entre 6 e 7, para tal ajuste utilizou-se soluções de hidróxido de sódio ( $\mathrm{NaOH}$ marca Quimex) e ácido clorídrico ( $\mathrm{HCl}$ marca Vetec) 0,01 mol.L ${ }^{-1}$.

As amostras permaneceram em agitação $(180 \mathrm{rpm})$ por $24 \mathrm{~h}$ em shaker à $20^{\circ} \mathrm{C}$. Novamente as amostras foram lidas em espectrofotômetro onde obteve-se os dados de absorbância. A partir das magnitudes da banda de absorção foi associada diretamente a concentração do corante na solução e, assim determinouse a capacidade de adsorção dos carvões e as constantes referentes às isotermas de Langmuir e Freundlich. O método matemático proposto por Langmuir em 1916 assume que a adsorção ocorre em monocamada, na qual a energia de adsorção é distribuída homogeneamente e a distribuição de moléculas adsorvidas ocorre de maneira uniforme. Esta isoterma é fundamentada nas hipóteses de que todas as moléculas adsorvem sobre sítios definidos e, que cada sítio pode ser ocupado por apenas uma molécula, a energia de adsorção de cada sítio é igual e quando moléculas ocupam sítios vizinhos a outras moléculas adsorvidas não há interações entre estas (COLPANI, 2012). Pode-se expressar a quantidade adsorvida em função da concentração na fase fluida em equilíbrio conforme a Equação 5:

$$
\mathrm{q}_{e}=\frac{q_{m} * K * C_{e}}{1+K * C_{e}}
$$

Onde:

$\mathrm{q}_{e}=$ quantidade adsorvida na fase sólida no equilíbrio (mg.g $\mathrm{g}^{-1}$ ).

$\mathrm{q}_{m}=$ capacidade máxima de adsorção, relacionada à cobertura de uma monocamada (mg. ${ }^{-1}$ ).

$\mathrm{K}=$ constante de equilíbrio de adsorção (L.mg ${ }^{-1}$ ).

$\mathrm{C}_{e}=$ concentração na fase líquida, no equilíbrio
(mg.L $\left.\mathrm{L}^{-1}\right)$.

Já, a teoria de adsorção descrita por Freundlich estabelece uma relação entre a quantidade de material adsorvido e a concentração do material na solução. A equação empírica proposta considera a sorção em superfícies heterogêneas ou superfícies com sítios de afinidades variadas, sendo assumido que os sítios com ligação mais forte são ocupados primeiro e que a força de ligação diminui com o aumento do grau de ocupação do sítio, ou seja, prevendo a existência de multicamadas. O modelo matemático descrito na Equação 6 sugere que a energia de adsorção decresce logaritmicamente à medida que a superfície vai se tornando coberta pelo soluto, o que a diferencia da equação de Langmuir (COUTO, 2009).

$\mathrm{q}_{e}=\mathrm{K}_{f}^{*} \mathrm{C}_{e}^{1 / n}$

Onde:

$\mathrm{q}_{e}=$ quantidade adsorvida na fase sólida no equilíbrio (mg.g $\left.{ }^{-1}\right)$.

$\mathrm{C}_{e}=$ concentração na fase líquida no equilíbrio (mg.L $\mathrm{L}^{-1}$ ).

$\mathrm{K}_{f}=$ afinidade do adsorvente

$\left(\mu \mathrm{g} \cdot \mathrm{mg}^{-1} \cdot\left(\mathrm{L} \cdot \mu \mathrm{g}^{-1}\right)^{1 / n}\right)$.

$\mathrm{n}$ = grau de heterogeneidade da superfície.

Os parâmetros empíricos de Freundlich são constantes que dependem de diversos fatores experimentais tais como temperatura, área superficial do adsorvente e do sistema particular a ser estudado. Essas constantes se relacionam com a distribuição dos sítios ativos e a capacidade de adsorção do adsorvente. O expoente $1 / \mathrm{n}$ também fornece uma indicação se a isoterma é favorável ou desfavorável, sendo valores de $\mathrm{n}$ no intervalo de 1 a 10 representativos de condições de adsorção favoráveis (COLPANI, 2012). Os ensaios de isoterma de adsorção foram conduzidos em triplicata. 


\section{Determinação do ponto de carga zero (PCZ)}

Para a determinação do ponto de carga zero pesou-se $0,2 \mathrm{~g}$ de carvão ativado que foram dispostas em 8 erlemneyers, a cada qual adicionou-se $100 \mathrm{~mL}$ de uma solução de cloreto de sódio $\left(\mathrm{NaCl}\right.$ marca Vetec) $0,01 \mathrm{~mol} . \mathrm{L}^{-1}$. Variou-se o pH entre 1, 2, 3, 4, 6, 8, 10 e 12 para tal, utilizou-se soluções de $\mathrm{HCl}$ e $\mathrm{NaOH}$ a 0,5 mol.L ${ }^{-1}$, sendo que estas são utilizadas justamente para ajustar o $\mathrm{pH}$. Os erlenmeyers foram encaminhados ao shaker, por onde permanecem $24 \mathrm{~h}$, sob agitação moderada e temperatura ambiente. Em seguida, determinou-se novamente o $\mathrm{pH}$ a fim de verificar qual a variação do mesmo após decorridas as $24 \mathrm{~h}$ de processo, conforme sugerido por Guilarduci et al. (2006) com algumas adaptações.

O ponto de carga zero (PCZ) significa uma igualdade entre a quantidade de cargas negativas e cargas positivas, ou seja, quando a superfície do adsorvente possui carga neutra. A determinação do PCZ de um carvão é de extrema relevância para aplicações de adsorção em que o adsorvato alvo possui estado aniônico ou catiônico. Quando o $\mathrm{pH}$ da solução é maior que o PCZ, sua carga superficial total ou externa estará carregada negativamente e a adsorção de cátions será favorecida, devido à atração eletrostática. Por outro lado, em pHs inferiores ao PCZ, a carga na superfície do carvão será predominantemente positiva, favorecendo então a adsorção de ânions (CLARK, 2010). Os ensaios de ponto de carga zero foram conduzidos em triplicata.

\section{RESULTADOS E DISCUSSÃO}

\section{Análise morfológica}

A capacidade de adsorção de um material adsorvente depende diretamente de sua área superficial, portanto o conhecimento desta é de suma importância para a análise detalhada do material empregado em determinado processo.

$\mathrm{A}$ amostra $\mathrm{C} 1$ quando submetido à análise de BET apresentou uma área superficial de $497,461 \mathrm{~m} 2 . \mathrm{g}^{-1}$, volume do poro de 0,5114 cc.g ${ }^{-1}$ e tamanho do poro de 17,72 Å. Já, a amostra $\mathrm{C} 2$, apresentou área superficial de $513,988 \mathrm{~m}^{2} \cdot \mathrm{g}^{-1}$, volume do poro de 0,4306 cc. ${ }^{-1}$ e tamanho do poro de $16,75 \AA$ A. Resende et al. (2007) estudaram a capacidade de adsorção de cromo (VI) em carvão ativado preparado a partir de frações de PVA (preto, verde, ardido) do café, ativado quimicamente com cloreto de zinco 1:1 e posterior carbonização a $500^{\circ} \mathrm{C}$ por $3 \mathrm{~h}$ obtiveram um carvão ativado apresentando área superficial de $889 \mathrm{~m} 2 . \mathrm{g}^{-1}$, sendo esta maior do que a obtida no presente estudo.

Lamine et al. (2014), utilizaram a borra de café oriunda de uma cafeteira para a obtenção de carvão ativado. A borra foi lavada, secada e peneirada antes do processo de ativação. Em seguida, impregnadas com ácido fosfórico (H3PO4) em diferentes concentrações por $18 \mathrm{~h}$ e, depois carbonizado a 600 e $700^{\circ} \mathrm{C}$ durante $1 \mathrm{~h}$. A área superficial resultante foi de 176 e $186 \mathrm{~m}^{2} \cdot \mathrm{g}^{-1}$, respectivamente. Os produtos resultantes foram testados para a adsorção de fenol.

Pereira et al. (2008) avaliaram a adsorção dos corantes orgânicos azul de metileno e vermelho reativo, utilizando um carvão ativado obtido a partir do resíduo sólido do fruto do cafeeiro (casca). A casca foi seca a $110^{\circ} \mathrm{C}$ por $24 \mathrm{~h}$, em seguida tratada com cloreto de ferro nonahidratado $(\mathrm{FeCl} 3.9 \mathrm{H} 2 \mathrm{O})$ na proporção 1:1 em massa e carbonizado nas temperaturas de 200,280 e $400^{\circ} \mathrm{C}$ durante $3 \mathrm{~h}$. O carvão pirolisado a $200^{\circ} \mathrm{C}$ não sofreu ativação, a $280 \mathrm{e}$ $400^{\circ} \mathrm{C}$ a área superficial foi de $965 \mathrm{~m}^{2} \cdot \mathrm{g}^{-1} \mathrm{e}$ $303 \mathrm{~m}^{2} . \mathrm{g}^{-1}$, respectivamente.

Logo, percebe-se que a área superficial é dependente do material precursor a ser utilizado, o agente ativante e sua proporção, tempo de ativação, temperatura e tempo de carbonização. O que geralmente acontece, mas, não pode ser tomado como regra é que em baixas temperaturas de carbonização geralmente a área superficial é reduzida. Ainda, a ativação química apresenta vantagens quando comparada à ativação física, como menor temperatura de carbonização e maior rendimento, tendo em vista que o ácido acelera o processo de degra- 
Tabela 1: Parâmetros cinéticos determinados para o modelo de pseudoprimeira ordem para as amostras C1 e C2

\begin{tabular}{ccccc}
\hline Amostra & q $_{e}$ (exp.)mg.g & qe(calc.)mg.g $^{-1}$ & K2g.mg & \\
\hline C1 & . $\mathbf{m i n}^{-1}$ & $\mathbf{R}^{2}$ \\
C2 & 50,67 & 53,069 & 0,023 & 0,8856 \\
\hline
\end{tabular}

Tabela 2: Parâmetros cinéticos determinados para o modelo de pseudosegunda ordem para as amostras C1 e C2

\begin{tabular}{ccccc}
\hline Amostra & q $_{e}$ (exp.)mg.g & qe(calc.)mg.g $^{-1}$ & K2g.mg $^{-1} \cdot \mathbf{m i n}^{-1}$ & $\mathbf{R}^{2}$ \\
\hline C1 & 50,67 & 103,09 & 0,00111 & 0,9990 \\
C2 & 62,56 & 62,89 & 0,01621 & 0,9994 \\
\hline
\end{tabular}

dação e posterior reorganização das estruturas (LIMA, 2010).

\section{Cinética de adsorção}

A cinética de adsorção do corante azul de metileno na concentração de $100 \mathrm{mg} . \mathrm{L}^{-1}$ para os adsorventes obtidos nas temperaturas de carbonização de 500 (amostra C1) e $600{ }^{\circ} \mathrm{C}$ (amostra C2), pode ser observado na Figura 1, sendo os resultados ajustados pelos modelos de cinética de pseudoprimeira ordem e pseudossegunda ordem. (a)

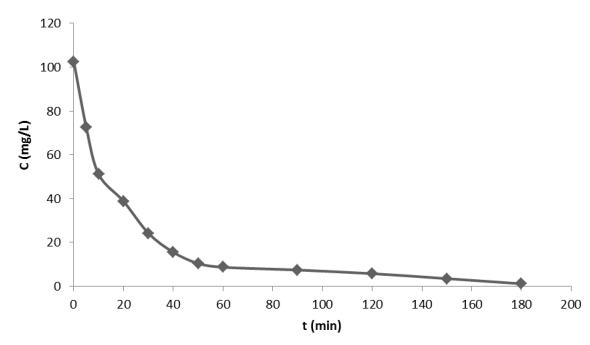

(b)

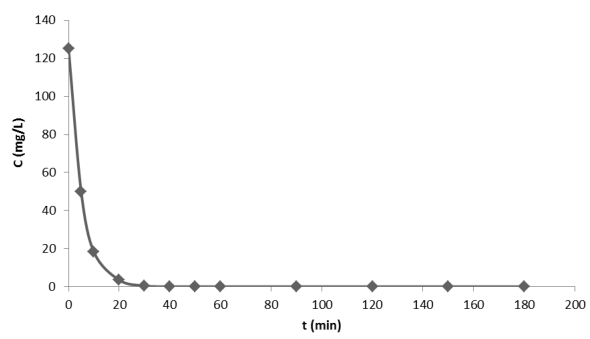

Figura 1: Cinética de adsorção do corante azul de metileno na concentração de $100 \mathrm{mg} . \mathrm{L}^{-1}$ para os adsorventes obtidos nas temperaturas de carbonização de 500 (a) e $600^{\circ} \mathrm{C}(b)$.

Pode-se observar que a concentração real do corante azul de metileno para o ensaio de cinética de adsorção para a amostra C1 e C2 foi de 102,479 e $125,125 \mathrm{mg} . \mathrm{L}^{-1}$, respectivamente. Como é possível observar em ambas as situações, tanto para a amostra $\mathrm{C} 1$ quanto para $\mathrm{C} 2$, 
Tabela 3: Parâmetros das isotermas de Langmuir e Freundlich para o carvão ativado carbonizado a $500^{\circ} \mathrm{C}$

\begin{tabular}{ccccccc}
\hline \multicolumn{3}{c}{ Langmuir } & \multicolumn{4}{c}{ Freundlich } \\
\hline $\mathbf{q}_{\text {max }}$ mg.g $^{1}$ & $\mathbf{K}^{\left(\mathbf{L} \cdot \mathbf{m g}^{1}\right)}$ & $\mathbf{R}^{2}$ & $\mathbf{1 / N}$ & $\mathbf{N}$ & $\left.\mathbf{K}_{F}\left(\mathbf{( m g . g}^{1}\right) .(\mathbf{L} \cdot \mathbf{m g 1})^{1 n}\right)$ & $\mathbf{R}^{2}$ \\
588,235 & 2,125 & 0,9922 & 0,513 & 1,949 & 8,167 & 0,9357 \\
\hline
\end{tabular}

Tabela 4: Parâmetros das isotermas de Langmuir e Freundlich para o carvão ativado carbonizado a $600^{\circ} \mathrm{C}$

\begin{tabular}{ccccccc}
\hline \multicolumn{3}{c}{ Langmuir } & \multicolumn{4}{c}{ Freundlich } \\
\hline $\mathbf{q}_{\text {max }}$ mg.g $^{1}$ & $\mathbf{K}^{\left(\mathbf{L} . \mathbf{m g}^{1}\right)}$ & $\mathbf{R}^{2}$ & $\mathbf{1 / N}$ & $\mathbf{N}$ & $\mathbf{K}_{F}$ ((mg.g $\left.\left.^{1}\right) .(\mathbf{L} \cdot \mathbf{m g 1})^{1 n}\right)$ & $\mathbf{R}^{2}$ \\
156,250 & 8,000 & 0,8732 & 0,322 & 3,104 & 51,019 & 0,9755 \\
\hline
\end{tabular}

a concentração de poluente no efluente diminui gradativamente com o passar do tempo, isso se deve a eficiência do carvão que retêm em seus poros as moléculas do corante azul de metileno. Porém, para a amostra $\mathrm{C} 1$ nota-se que é necessário um período de tempo maior para remover na totalidade o corante azul de metileno. Assim, verifica-se que o carvão que demostrou a melhor eficiência em remoção foi a amostra $\mathrm{C} 2$, haja vista que apresentou uma concentração nula de azul de metileno em apenas 40 min de ensaio.

Ferreira et al. (2007) avaliaram a viabilidade de utilização do resíduo proveniente da indústria de café solúvel, borra de café, como adsorvente para remoção do corante azul de metileno presente em soluções aquosas. Para todas as concentrações iniciais de azul de metileno avaliadas, observou-se que a adsorção ocorreu em taxas mais altas nas primeiras $2 \mathrm{~h}$ de contato do adsorvente com o adsorvato. Observou-se ainda que o equilíbrio foi atingido após $12 \mathrm{~h}$ e que o percentual de remoção de azul de metileno variou de $52 \%$ (500 mg. $\mathrm{L}^{-1}$ de corante) a $98 \%$ (50 mg. $\mathrm{L}^{-1}$ de corante) em função da concentração inicial do corante. (a)

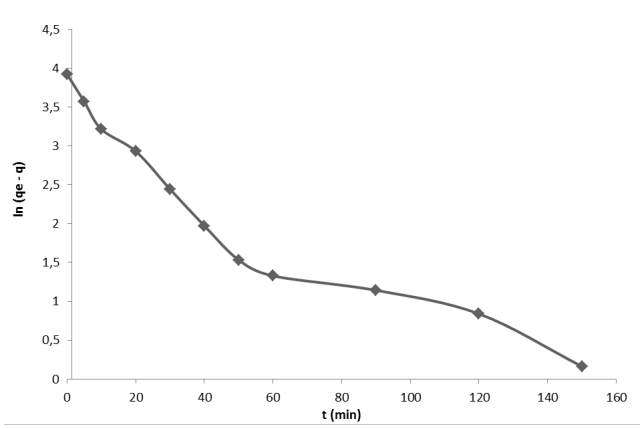

(b)

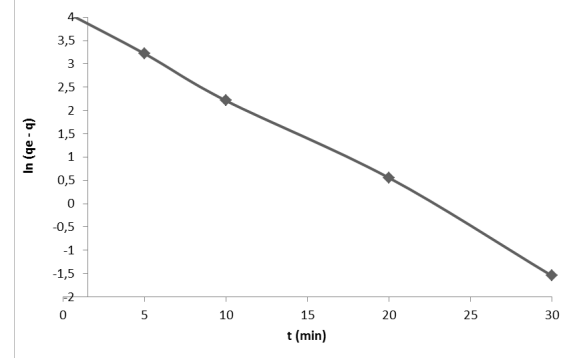

Figura 2: Linearização para o modelo de pseudoprimeira ordem para a amostra C1 (a) e C2 (b)

Leal et al. (2012) estudaram a adsorção do corante azul de metileno utilizando-se como material adsorvente resíduos de babaçu. Constataram que o tempo de equilíbrio para o processo é de $30 \mathrm{~min}$, em um pH de 7 e $250 \mathrm{mg} . \mathrm{L}^{-1}$ de azul de metileno o percentual de remoção 
foi de aproximadamente $88 \%$.

Menegaro et al. (2012) avaliaram a viabilidade do uso de resíduos de cerâmica vermelha para adsorção do azul de metileno com posterior aplicação em filtros em camadas para efluentes de indústrias têxteis. Concluíram que para um tempo de retenção inferior a $10 \mathrm{~min}$ na coluna, atingiu-se uma eficiência adsortiva de aproximadamente $90 \%$.

Tramontin et al. (2001) utilizaram os finos de carvão para preparo de um carvão ativado no intuito de promover a adsorção do corante azul de metileno. A ativação dos finos de carvão ocorreu por tratamento térmico em temperaturas variando de $200^{\circ} \mathrm{C}$ e $700^{\circ} \mathrm{C}$ em atmosfera oxidante de dióxido de carbono. Todas as amostras de carvão ativado apresentaram alto poder de adsorção frente ao corante azul de metileno, sendo que o maior percentual de remoção foi obtido a $300^{\circ} \mathrm{C}$ e a amostra que teve o pior desempenho foi a carbonizada a $700^{\circ} \mathrm{C}$, sendo os percentuais de remoção de $96,63 \%$ e $92,13 \%$, respectivamente.

Fonseca (2013) estudou o potencial da borra de café como precursora na produção de carvão ativado e sua aplicação na adsorção de fenol. As amostras de carvão foram ativadas com soluções de cloreto de zinco $\left(\mathrm{ZnCl}^{2}\right)$ ou hidróxido de potássio $(\mathrm{KOH})$ (ambas com concentração 5 mol.L ${ }^{-1}$ ) e carbonizadas em forno de micro-ondas por $30 \mathrm{~min}$. A amostra de carvão ativado com hidróxido de potássio apresentou os melhores resultados quando comparada ao carvão ativado com $\mathrm{ZnCl}^{2}$, sendo que em uma concentração de fenol de $166,67 \mathrm{mg}^{-g^{-1}}$ apresentou um percentual de remoção de $92 \%$.

As linearizações da relação entre a concentração e o tempo são apresentadas nas Figuras 2 e 3, representando respectivamente os modelos de pseudoprimeira e pseudossegunda ordem.

A avaliação quantitativa dos modelos foi realizada pela comparação dos coeficientes de determinação $\left(\mathrm{R}^{2}\right)$ e pelos valores de $\mathrm{q}_{e}$ calculado versus $\mathrm{q}_{e}$ obtido experimentalmente para os modelos de pseudoprimeira e pseudossegunda ordem, conforme apresentado nas Tabelas 1 e 2 .
Conforme observado nas Tabelas 1 e 2, os dados experimentais obtidos enquadraram-se melhor no modelo de pseudossegunda ordem, sendo que este modelo foi o que melhor se ajustou por apresentar os menores desvios entre a quantidade adsorvida calculada e experimental no equilíbrio e os maiores coeficientes de determinação para ambas as amostras. Logo, este modelo indica que o processo de adsorção é de natureza química e taxa controlada. Contrariamente ao modelo de pseudoprimeira ordem o modelo de pseudossegunda ordem prediz o comportamento de adsorção durante todo o tempo do processo de adsorção (CLARK, 2010).

(a)

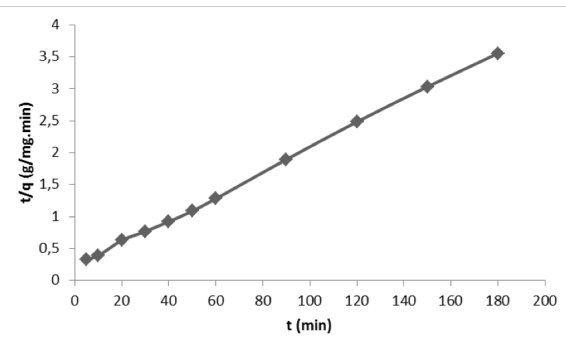

(b)

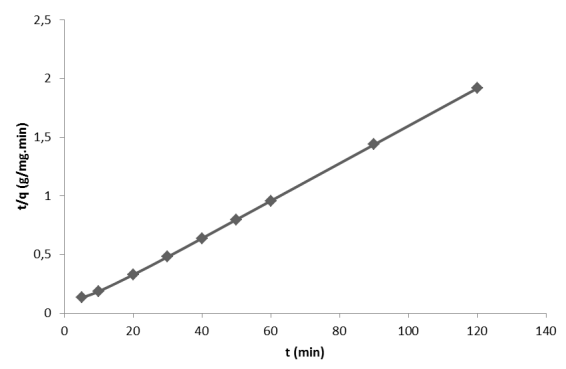

Figura 3: Linearização para o modelo de pseudosegunda ordem para a amostra C1 (a) e C2 (b)

\section{Isotermas de Adsorção}

O equilíbrio de adsorção de azul de metileno foi expresso em termos de isotermas de adsorção, sendo realizado o ajuste dos dados experimentais através dos modelos de Langmuir e Freundlich, conforme observa-se nas Figuras 4 e 5. As Tabelas 3 e 4 apresentam os 
valores para os parâmetros das isotermas de adsorção de Langmuir e Freundlich para os dois carvões obtidos, respectivamente.

(a)

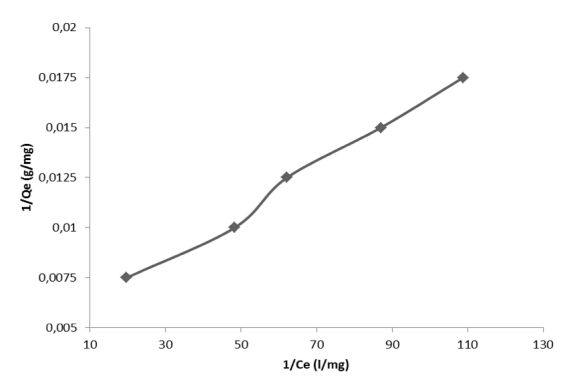

(b)

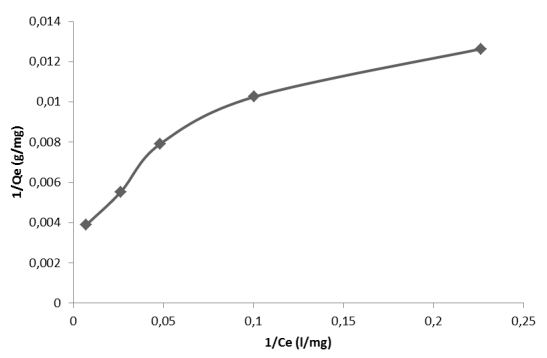

Figura 4: Linearização da isoterma de adsorção de Langmuir para as amostras $C 1$ (a) e C2 (b)

Avaliando-se as Tabelas 3 e 4 pode-se constatar que para a amostra C1, o modelo de isoterma que melhor se adequa ao processo é a Isoterma de Langmuir por apresentar um coeficiente de correlação de 0,9922 , sendo maior quando comparado à Isoterma de Freundlich, que resulta em um valor de coeficiente de correlação de 0,9357 . Já, para a amostra C2, pode-se perceber que o modelo de isoterma que melhor representa o processo é a Isoterma de Freundlich devido, a apresentar um coeficiente de correlação de 0,9755 , sendo maior quando comparado à Isoterma de Langmuir, que resulta em um valor de $R^{2}$ de 0,4131 . (a)

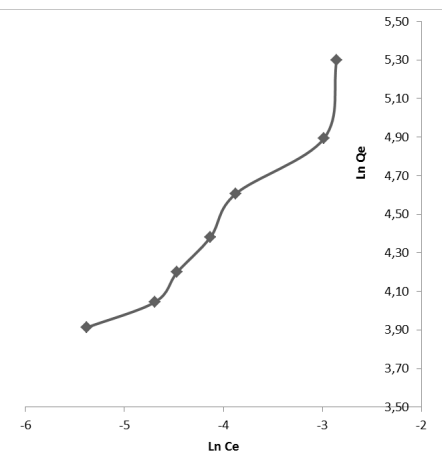

(b)

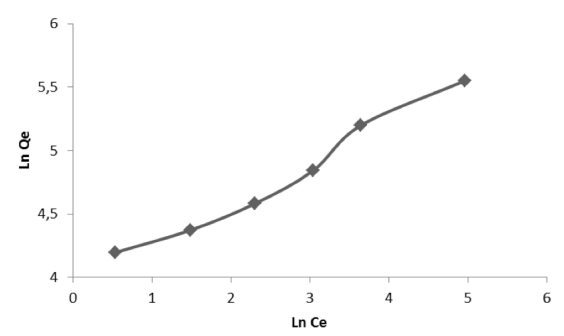

Figura 5: Linearização da isoterma de adsorção de Freundlich tanto para as amostras C1 (a) e C2 (b)

\section{Ponto de carga zero}

As curvas experimentais para a determinação do ponto de carga zero dos carvões ativados produzidos estão apresentadas nas Figuras 6 e 7. Analisando-se as Figuras 6 e 7 é possível verificar o ponto de carga zero, sendo estes valores na faixa de 2,001-2,009 para C1 e 2,0013 para $\mathrm{C} 2$, valores estes já esperados devido à ativação química ser realizada por um ácido, logo o ponto de carga zero deve apresentar valores abaixo do pH neutro. Nunes (2008) produziu um carvão sem ativação química, no qual obteve um PCZ básico, próximo a 12. Desta forma, em soluções com $\mathrm{pH}$ acima do ponto de carga zero, as cargas superficiais do carvão estarão negativas, favorecendo a adsorção de cátions. E em soluções de $\mathrm{pH}$ abaixo deste ponto as cargas superficiais estarão positivas, favorecendo a adsorção de ânions. 


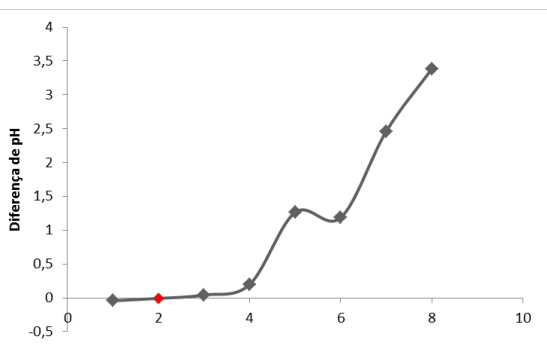

Figura 6: Curva experimental para determinação do PCZ do carvão ativado carbonizado a $500{ }^{\circ} \mathrm{C}$

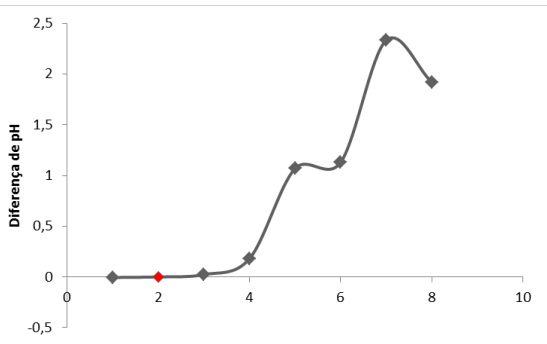

Figura 7: Curva experimental para determinação do PCZ do carvão ativado carbonizado a $600^{\circ} \mathrm{C}$

Logo, o pH da solução deve estar acima do ponto de carga zero, pois o corante azul de metileno possui caráter catiônico, sendo favorecida sua adsorção nessa condição. Han, Wang e Ma (2011) estudaram as características de adsorção de azul de metileno em material de biomassa de baixo custo (folha de lótus) e verificaram que o aumento do $\mathrm{pH}$ da solução foi útil para a adsorção de azul de metileno no adsorvente. A medida que o $\mathrm{pH}$ inicial da solução aumentou de 1,6 para 3,6, o valores de qe aumentaram rapidamente de 24,9 para 88,6 $\mathrm{mg} \mathrm{g}^{-1}$. Isso é devido a reação do corante catiônico com as hidroxilas $\mathrm{OH}$-. À medida que o pH da solução aumentou, o número de sítios carregados negativamente sobre a superfície do adsorvente aumentou, o que pode resultar no aumento da adsorção de moléculas de corante catiônico devido à atração eletrostática.

\section{Conclusões}

A partir dos resultados obtidos verificou-se que o café torrado que passou por um processo prévio de extração do seu óleo bruto pode ser utilizado eficazmente na remoção do corante azul de metileno. A amostra C2 apresentou maior área superficial, menor volume e tamanho de poro quando comparado à C1. Quando submetidos à cinética de adsorção, $\mathrm{C} 2$ foi mais eficaz na remoção do corante azul de metileno , haja vista que apresentou uma concentração nula do mesmo em apenas $40 \mathrm{~min}$ de ensaio.

O mecanismo de adsorção de pseudossegunda ordem foi o que melhor se ajustou para ambas as amostras ( $\mathrm{C} 1$ e $\mathrm{C} 2$ ) por apresentar os menores desvios entre a quantidade adsorvida calculada e experimental no equilíbrio e os maiores coeficientes de determinação. Para a amostra $\mathrm{C} 1$ a isoterma de adsorção que melhor se adequou aos ensaios realizados foi a isoterma de Langmuir. Em contrapartida, para C2 quem melhor se adequou aos ensaios realizados foi a isoterma de Freundlich. O ponto de carga zero obtido para $\mathrm{C} 1$ varia na faixa de 2,001 a 2,009 e para C2 2,0013.

\section{REFERÊNCIAS}

AMARASEKARE, P.; NISBET, R.M. Spatial heterogeneity, source-sink dynamics, and the local coexistence of competing species. The American Naturalist, Chicago, v.158, p. 572584, 2001.

BRUM, S.S.; BIANCHI, M. L.; SILVA, V.L.; GONÇALVES, M.; GUERREIRO, M.C.; OLIVEIRA, L.C.A. Preparação e caracterização de carvão ativado produzido a partir de resíduos do beneficiamento do café Química Nova, Brasil, v.31, p. 1048-1052, 2007.

BUGIERECK, A.M.; BEHLING, S.M.; MELLO, J.M.M.; FIORI, M.A.; COLPANI, G.L.; DAL MAGRO, J. Avaliação da capacidade adsortiva de carvão ativado quimicamente a partir de casca de banana Acta Ambiental Catarinense, Brasil, v.10, p. 45-60, 2013. 
CLARK, H.L.M. Remoção de fenilalanina por adsorvente produzido a partir da torta prensada de grãos defeituosos de café 2010. 115 p. Dissertação (mestrado em Ciência de Alimentos - UFMG. Belo Horizonte, 2010.

CLAUDINO, A. Preparação de Carvão ativado a partir de turfa e sua utilização na remoção de poluentes 2003. 90 p. Dissertação (mestrado em Engenharia Química UFSC. Florianópolis, 2003.

COLPANI, G.L. Preparação e caracterização de adsorventes para a remoção de surfactantes aniônicos em água 2012. 102 p. Dissertação (mestrado em Engenharia Química - UFSC. Florianópolis, 2012.

CONAB - Companhia Nacional de Abastecimento. Acompanhamento da safra brasileira de café v. 2 - Safra 2016, n.1 - Primeiro Levantamento, Brasília, p. 1-68, 2016.

COUTO, G.M. Utilização de serragem de Eucalyptus sp. na preparação de carvões ativados 2009. 106 p. Dissertação (mestrado em Ciência e Tecnologia da Madeira - UFLA. Lavras, 2009.

EMBRAPA - Empresa Brasileira de Pesquisa Agropecuária. Produção de briquetes e péletes a partir de resíduos agrícolas, agroindustriais e florestais ISSN 2177 - 4439, Brasília, 2012.

FERREIRA, M.E.; FRANÇA, A.S.; OLIVEIRA, L.S. Avaliação da dinâmica e equilíbrio de adsorção de azul de metileno em borra de café VII Congresso Brasileiro de Engenharia Química de Iniciação Cientifica - COBEQ/IC - UFMG. Belo Horizonte, 2007.

FONSECA, A.C.C. Produção de carvão ativado utilizando como precursor borra de café e sua aplicação na adsorção de fenol 2013. 51 p. Monografia (Tecnologia em Processos Ambientais - UTFRP. Curitiba, 2013.

GIRALDO, L; PIRAJAN, J.C.M. Synthesis of activated carbon mesoporous from coffee waste and its application in adsorption zinc and mercury ions from aqueous solution E-Journal of Chemistry, 2012.

GUILARDUCI, V.V.S.; MESQUITA, J.P.; MARTELLI, P.B.; GORGULHO, H.F. Adsorção de fenol sobre carvão ativado em meio alcalino Química Nova, Brasil, v.29, p. 1226-1232, 2006.

bibitem[GOMIDE, 1980] GOMIDE, R. Operações unitárias São Paulo: Ed. do Autor, v. 5, 1980.

HAMEED, B.H.; DIN, A.T.M.; AHMAD, A. L. Adsorption of methylene blue onto bamboo-based activated carbon: Kinetics and equilibrium studies Journal of Hazardous Materials, Malasia, v.141, p., 819-825, 2007.

HAN, X.; WANG, W.; MA, X. Adsorption characteristics of methylene blue onto low cost biomass material lotus leaf Chemical Engineering Journal, v.171, p. 1-8, 2011.

KHENNICHE, L.; BENISSAD-AISSANI, F. Adsorptive removal of phenol by coffee residue activated carbon and commercial activated carbon: Equilibrium, Kinetics, and Thermodynamics Journal of Chemical e Engineering, v.55, p. 4677-4686, 2010.

KUNZ, A.; PERALTA-ZAMORA, P.; MORAES, S. G.; DURAN, N. Novas tendências no tratamento de efluentes têxteis Química Nova, Brasil, v.25, p. 78-82, 2010.

LAMINE, S. M.; RIDHA, C.; MAHFOUD, H. M.; MOUAD, C.; LOTFI, B.; AL-DUJAILI, A. $\mathrm{H}$. Chemical activation of an Activated carbon Prepared from coffee residue Energy Procedia, v.50, p. 393-400, 2014.

LEAL, P. V. B.; GREGÓRIO, A. M.; OTONI, E.; SILVA, P. R.; KRAUSER, M. O.; HOLZBACH, J. C. Estudo da adsorção do corante azul de metileno em resíduos de babaçu Journal of Biotechnology and Biodiversity, Brasil, v.3, p. 166-171, 2012.

LIMA, R.B. Processo para a produção de carvão ativo a partir do subproduto resultante 
da lixívia alcalina da cinza da casca do arroz 2010. 111 p. Dissertação (mestrado em Engenharia Química - UFSC. Florianópolis, 2010.

LOPES, T.J.; VIEIRA, M.A.; OLIVEIRA, M.; PEREIRA, B.A.; SILVA, L.L.; FERNANDES, S.C.; SAVIO, J.; COSTELLI, M.C. Obtenção e aplicação de carvão do pseudofruto da uvajapão (Hovenia dulcis Thunberg) no tratamento de efluentes líquidos com corantes Acta ambiental catarinense, Brasil, v.10, p. 2944, 2013.

MENEGARO, D.A.; MIGUEL, T.F.; BETIOLI, A.M.; DOMINGUINI, L. Cinética de adsorção de azul de metileno por resíduos de cerâmica vermelha 2012. $1^{\circ}$ Simpósio de Integração Científica e Tecnológica do Sul Catarinense - SICT-Sul - Criciúma, 2010.

MONTEIRO, S.M. Mesocarpo de coco verde (cocos nucífera) e pó de serragem da Tatajuba (Bagassa Guianensis Aubi) como adsorventes em meio aquoso 2010. 83 p. Dissertação (mestrado em Química - UFMA. São Luís, 2010.

NEUMANN, M.G.; GESSNER, F.; CIONE, A.P.P.; SARTORI, R.A.; CAVALHEIRO, C.C.S. Interações entre corantes e argilas em suspensão aquosa Química Nova, Brasil, v.23, p. 818-824, 2000.

NUNES, A.A. Produção de adsorvente a partir de resíduo sólido da produção de biodiesel de óleo de café 2008. 78 p. Dissertação (mestrado em Engenharia Química - UFMG. Belo Horizonte, 2008.

OLIVEIRA, E.H.C. Adsorção de corantes da indústria têxtil (Indosol) em resíduos industriais (Lama vermelha e argila esmectita) 2010. 89 p. Dissertação (mestrado em Engenharia Química - UFPE. Recife, 2010.
PHATAI, P.; UTARA, S.; HATTHAPANIT, N. Removal of methyl violet by adsorption onto activated carbon derived from coffee residues Advanced Materials Research, v.864867, p. 710-714, 2014.

PEREIRA, E.; OLIVEIRA, L.C.A.; VALLONE, A.; SAPAG, K.; PEREIRA, M. Preparação de carvão ativado em baixas temperaturas de carbonização a partir de rejeitos de café: utilização de $\mathrm{FeCl} 3$ como agente ativante Química Nova, Brasil, v.31, p. 1296-1300, 2008.

RESENDE, E.C.; RAMOS, P.H.; AVELAR, F.F.; GUERREIRO, M.C.; GONÇALVES, M. Adsorção de cromo (VI) em carvão ativado preparado a partir de rejeitos agroindustriais 2007. $30^{\mathrm{a}}$ Reunião Anual da Sociedade Brasileira de Química - 2007. Florianópolis, 2010.

SENTHILKUMAAR, S.; VARADARAJAN, P.R.; PORKODI, K.; SUBBHURAAM, C. V. Adsorption of methylene blue onto jute fiber carbon: kinetics and equilibrium studies Journal of Colloid and Interface Science, v.284, p. 78-82, 2005.

SHENG, J.; XIE, Y.; ZHOU, Y. Adsorption of methylene blue from aqueous solution on pyrophyllite Applied Clay Science, v.46, p. 422-424, 2009.

TRAMONTIN, D.P.; PETERSON, M.; PIZZOLO, J.P.; PIZZOLO, J.P. Adsorção do corante básico (azul de metileno) por carvão ativado preparado a partir de finos de carvão III Congresso Brasileiro de Carvão Mineral, UFRGS. Gramado, 2011.

WU, Y.; ZHANG, L.; GAO, C.; MA, J.; MA, X.; HAN, R. Adsorption of copper ions and methylene blue in a single and binary system on wheat straw Journal Chemical Engineering, v.54, p. 3229-3234, 2009. 